\title{
Number of Regional Lymph Nodes Positive
}

National Cancer Institute

\section{Source}

National Cancer Institute. Number of Regional Lymph Nodes Positive. NCI Thesaurus.

Code C160907.

The number of regional nodes examined by the pathologist and found to contain metastases. 